\title{
Uma análise discursiva do livro didático de Biologia na Educação para jovens e adultos
}

\author{
A discursive analysis of the biology textbooks in education for young people \\ and adults
}

\begin{abstract}
Josete Rocha dos Santos
Mestre em Linguística pelo Programa de Pós-Graduação do Projeto de Estudos e Usos da Língua (PEUL) da Faculdade de Letras da Universidade Federal do Rio de Janeiro (UFRJ) e Doutoranda em Educação em Ciências pelo Programa de Pós-Graduação em Educação em Ciências do Instituto NUTES (UFRJ). Professora do Ensino Médio da Secretaria Estadual de Educação do Estado do Rio de Janeiro desde 1998. Rio de Janeiro, Brasil. rochajosetefreitas@gmail.com
\end{abstract}

Andréa Costa da Silva

Doutora e Mestre em Educação em Ciências e Saúde, pelo Programa de Pós-graduação em Educação em Ciências e Saúde (NUTES / UFRJ). Atua como docente no Programa de Pós-graduação em Ciências Aeroespaciais (PPGCA/UNIFA) e no Programa de Pós-graduação em Educação e Ciências e Saúde (PPGECS/UFRJ). Possui experiência na área de Educação, com ênfase em estudos e pesquisas nos seguintes temas: Educação em Saúde; Estudos Culturais e Educação; Gênero e Sexualidade; Literatura e Educação; Mulheres e Forças Armadas. Rua Divisória 30, casa 50, apto 102. Bento Ribeiro - Rio de Janeiro - RJ Brasil acostadasilva@gmail.com

Resumo: Pressupostos freireanos evidenciam como o conhecimento científico proposto pela escola deve ser associado ao saber do cotidiano. Assim, cidadania e letramento científico devem andar juntos e são ferramentas essenciais na busca por uma educação que contemple preceitos dos direitos humanos, presentes na Lei de Diretrizes e Bases da Educação. Transpor esse olhar para a Educação de Jovens e Adultos - EJA - é o desafio desse artigo, que analisa discursos presentes no livro didático de Biologia destinado aos alunos do Ensino Médio do Estado do Rio de Janeiro, na modalidade EJA. Com a Análise Crítica do Discurso verificamos que o significado identificacional está presente no livro didático, por meio dos pronomes pessoais "você" e "nós". Os resultados mostram uma tentativa do enunciador de mostrar proximidade do aluno usando mais o pronome "nós" nos textos. Ainda há muito a fazer no percurso de considerar a experiência do aluno nos conteúdos expressos nos livros.

Palavras-chave: Ensino de Ciências. Discurso. Biologia. Educação de Jovens e Adultos.

Abstract: Freirean assumptions show how the scientific knowledge proposed by schools should be associated with everyday knowledge. Thus, citizenship and scientific literacy must go together and are essential tools in the search for an education that includes human rights norms, present in the National Educational bases and Guidelines Law (Lei de Diretriz \es e Bases da Educação); transposing this view to Youth and Adult Education (Educação de Jovens e Adultos - EJA) is the challenge of this article, which analyzes present discourses in High School Biology textbooks, addressed to EJA students from the State of Rio de Janeiro. With the Critical Discourse Analysis, we verify whether the identificational meaning is present in the textbooks through the personal pronouns "you" and "we". The results indicate the speaker's attempt to show closeness to a student by using the pronoun "we" in the texts more frequently. There is still a lot to do when it comes to considering the student's experience in the content portrayed in these books.

Key-words: Science Teaching. Discourse. Biology. Youth and Adult Education. 


\section{Introdução}

“A educação é necessária para a sobrevivência do ser humano”, disse Gadotti (2013, p.12) e, com pressupostos freirianos, nos instiga a pensar a questão dos Direitos Humanos considerando o direito de todo ser humano a ter acesso à educação e à cultura, e, mais ainda, avança em entender essa garantia “[...] como direito à educação emancipadora” (GADOTTI, 2013, p. 23), ou seja, na contramão de um pensamento neoliberal, concebendo a educação em sua dimensão humanista. Gadotti nos diz que "Não podemos defender o direito à educação sem associá-lo aos outros direitos” (2013, p. 23), e, com isso, podemos pensar que o direito à educação não deve ser separado de outros direitos sociais. Dessa forma, para o autor, "os Direitos Humanos são todos interdependentes” (p.12). Pensando nessa dimensão ampliada, o direito à educação deve atender aos grupos sociais mais vulneráveis para oferecer ao sujeito a possibilidade de superação da pobreza e da exclusão social, investindo na ação de torná-lo "sujeito de direitos", sem esquecer o caráter político de todo ato de educar.

Por essa via, caminha a Lei de Diretrizes e Bases da Educação Nacional (LDB), Lei 9.394/96, quando materializa esse pensamento e nos permite olhar também para a Educação de Jovens e Adultos - EJA - como uma modalidade que, ao longo da história, teve seus direitos sociais negados. por isso, esta lei tornou-se importante por legitimar o direito aos jovens e adultos a uma educação que "deve restaurar, equalizar e qualificar" (PARECER CEB 11/2000, p. 37 e RESOLUÇÃO CEB 1/200).

Referindo-se ao panorama histórico da LDB, Lei 9394/96, no que tange à Educação de Jovens e Adultos, Di Pierro e Haddad nos dizem:

[...] os desafios relativos à educação de jovens e adultos seriam três: resgatar a dívida social representada pelo analfabetismo, erradicando-o; treinar o imenso contingente de jovens e adultos para a inserção no mercado de trabalho; e criar oportunidades de educação permanente. (DI PIERRO e HADDAD, 2015, p. 122).

Então, não é por acaso que Paulo Freire, em seu livro "Pedagogia da Autonomia", sugere que, ao trabalharmos com jovens e adultos, devemos estimulá-los e contribuirmos para uma educação que supere os obstáculos da não-ação social. Os conhecimentos científicos devem ser associados ao saber do cotidiano, ao que o aluno traz para a sala de aula. "A leitura de mundo deve vir antes da leitura da palavra” (FREIRE, 2018, p. 104). O saber científico deve levar os sujeitos a serem seres pensantes que saibam aplicar estes conhecimentos à sua vivência. 
Di Pierro e Haddad (2015) apontam para a visão de que os avanços educacionais em relação à EJA, no Brasil, passam por uma necessidade de mobilização da sociedade civil como o viés para reconhecer os jovens e adultos - que tiveram o acesso à escola negado por terem que ir ao mercado de trabalho -, como aqueles que têm direitos sociais à educação, antes restrita a crianças e adolescentes.

Mais especificamente, no contexto do ensino de Ciências, este objetivo assume um papel fundamental: levar o aluno a adotar uma perspectiva crítica, ser capaz de questionar os objetivos da própria ciência e propor eventuais mudanças, pois,

De fato, a adoção de perspectivas críticas, para a educação, distingue um letramento científico funcional onde os sujeitos se ajustam à sociedade contribuindo para o seu progresso, reforçando e consolidando relações, já estabelecidas, de um letramento científico emancipatório dentro do qual existe um engajamento no sentido de transformar não só sua própria condição na sociedade, como também a própria sociedade (MARTINS, 2008, p. 1, grifo nosso).

Ser letrado e alfabetizado cientificamente é saber aplicar os conteúdos científicos em contextos de participação social e política (MARTINS, 2008). Essa construção passa pelo uso do livro didático de Ciências, especificamente de Biologia, que aborda assuntos relacionados ao cuidado com o corpo e com o meio ambiente. Com base nisso, a linguagem da ciência não se resume à memorização de termos técnicos ou vocabulário específico.

Sendo assim, o objetivo deste trabalho é apresentar um recorte de pesquisa qualitativa realizada em livros didáticos de Biologia da Nova EJA, Ensino Médio, analisando excertos que trabalhem o significado identificacional (FAIRCLOUGH, 2001), responsável pela construção da imagem que criamos do outro. Com essa imagem poderemos observar se os alunos da EJA são identificados de forma distanciada ou não para transmitir o conteúdo da Ciência, a fim de considerá-los como sujeitos de seus direitos dentro da perspectiva de uma educação emancipatória (FREIRE, 2018).

Pensar o significado identificacional nos textos dos livros didáticos significa observar como o discurso identifica os atores sociais (FAIRCLOUGH, 2003), ou seja, como a imagem deste aluno é expressa por meio dos pronomes pessoais "você" e "nós". isso porque usamos os pronomes para referenciação de nós mesmos e do outro com quem dialogamos. Com base nos pressupostos teóricos e metodológicos da Análise Crítica do Discurso (ACD), Fairclough (2003) e de Chouliaraki e Fairclough (1999), consideramos que "[...] é por meio do significado identificacional que se pode 
ter acesso aos modos pelos quais os atores sociais emergem dos textos" (RESENDE e RAMALHO, 2016, p. 77).

Dentro deste estudo, observaremos os pronomes "você" - pronome pessoal de tratamento - e o pronome "nós" - pronome pessoal do caso reto - para ver como se organizam, como o discurso científico circula na sociedade, muitas vezes, de forma distanciada da realidade do aluno, o que não favorece a construção de posturas politicamente autônomas. A visão de mundo do enunciador, expressa pelos pronomes "você" e "nós", desenvolvida no estudo mais adiante, podem se remeter a eventos nos quais a tomada de decisão é individual - expressa no uso do pronome "você" - ou coletiva - expressa no uso do pronome "nós" - quando o enunciador se considera representado nessas ações de conhecimento científico. A forma como esses sujeitos são identificados e seus posicionamentos tornam-se importantes para constatar se o conhecimento científico é apresentado como verdade ou como possibilidade de ação; se há vozes enunciativas de autoridade presentes nestes discursos, relacionando conhecimentos científicos e conhecimentos cotidianos.

Com tais pressupostos, nos perguntamos: como os discursos presentes nos livros didáticos de Ciências representam o leitor, no caso deste trabalho, o aluno da EJA do Estado do Rio de Janeiro? A linguagem destes livros procura se aproximar da realidade do aluno ou se distancia?

Com tais inquietações, a seguir, avançamos em pontos conceituais importantes sobre a EJA, contextualizando a trajetória deste recorte educacional no Brasil em sua interface com o ensino de Ciências, pressupostos que balizam nosso estudo, para avançarmos na análise em seguida.

\section{Pontos importantes sobre a educação de jovens e adultos e a linguagem do livro didático de ciências}

A educação deve garantir o direito ao ser humano para construir a sua autonomia enquanto ser atuante na sociedade (FREIRE, 2018). Discutir estes aspectos requer pensarmos que a educação precisa orientar o sujeito para seu próprio querer, sua independência para decidir e, para isso, ele precisa estar capacitado para agir criticamente no mundo em que vive.

Se olharmos de forma retrospectiva, veremos que no século XVI, no Brasil Colônia, as primeiras formas de educação junto ao público adulto foram realizadas pelos jesuítas por meio da catequese, visando "alfabetizar" em português e impor, por meio do ensino da língua portuguesa, a religião católica aos indígenas e aos negros; na atualidade, olhar para a trajetória histórica das políticas educacionais no Brasil requer olhar para as várias expressões da EJA, pois há necessidade 
de que possamos observar camadas da sociedade, muitas vezes, excluídas de um processo educacional formal (ALVARENGA, 2010).

Segundo Di Pierro e Haddad (2015), o Brasil está entre os 53 países que ainda não atingiram e nem estão perto de atingir os objetivos de uma educação em que todos serão alfabetizados, apesar dos avanços registrados na frequência ao ensino fundamental e na ampliação do acesso ao ensino superior; segundo os autores, o Brasil, em 2015, ocupava a $8^{a}$ posição entre as nações com maior número de analfabetos adultos e a UNESCO avaliou que o país teria dificuldades para alcançar a meta de melhorar em 50\%os níveis de alfabetização de adultos até 2025.

Outras pesquisas nos dizem que a capacidade de intervenção das escolas e das experiências de EJA, na questão da exclusão social da juventude pobre, é limitada. No entanto, a escola poderá ser um espaço de encontro e expressão para seus alunos que, desde muito cedo, veem negado o direito à vivência plena da sua juventude (CARRANO et al, 2015). Como sugere Miguel Arroyo (2001), coloca-se o desafio de pensar qual o papel da EJA em tempos de exclusão. Segundo o autor, ao longo de décadas, os educadores da EJA, no Brasil, constituíram um legado a ser rememorado e radicalizado. Tal legado é marcado por alguns traços, como a situação de exclusão que caracteriza o seu público, fazendo urgir a questão da valorização da sua condição humana, a adoção de uma concepção humanista de educação e a abordagem da educação como um direito. A radicalização desse legado implica a superação das intervenções compensatórias que constituem a sua história. Gadotti, referindo-se à Educação de Adultos como Direito Humano, nos diz: "Reconhecemos que, entre nós, melhorou o acesso à escola, mas subsiste o problema da qualidade. A educação não está contribuindo para a redução da desigualdade.” (GADOTTI, 2013, p.24)

Di Pierro e Haddad (2015) endossam tal perspectiva e evidenciam que, tanto no Brasil quanto no exterior, o número de analfabetos jovens e adultos diminuiu lentamente e não houve um avanço significativo da escolaridade nesse grupo. Talvez a dificuldade esteja na consequência de políticas neoliberais e no aprofundamento das desigualdades sociais, cenário em que os estudantes da EJA não têm como ver os seus direitos garantidos.

Consideramos ser importante uma Educação de Jovens e Adultos aliada ao letramento científico - conhecimento científico importante ao aluno a ponto de permitir mudanças significativas nas formas de percepção e significação da realidade. Isso deve ocorrer por meio de um ensino de Ciências contextualizado à realidade deste aluno.

No início do século XX, esse ensino era mais pautado nas motivações de caráter humanista. Era mais normativo, mais preocupado em ajustar os sujeitos à sociedade para manutenção do status quo (KRASILCHIK, 2000). 
Mais tarde, no período de 1950 a 1970, Krasilchik (2000) afirma haver mais projetos de ensino nacionais e internacionais que valorizavam o método da construção de práticas e do raciocínio científico. Porém, a partir da ditadura militar, com o surgimento de um ensino mais profissionalizante, as disciplinas científicas tiveram a sua importância diminuída nos currículos.

Nesta fase atual, das Diretrizes e Bases da Educação Nacional - Lei 9394/96 (BRASIL, 1996), estamos ainda distantes de um Ensino de Ciências para todas e todos trabalhadores do país, mas, sem dúvida, já houve um avanço no crescimento da quantidade de alunos que frequentam a EJA (MACHADO, 2016) e há uma ênfase maior em se trabalhar os conteúdos de Ciências, a partir dos materiais educativos, aliando-os às questões sociopolíticas e ligadas ao cotidiano do aluno. Discutir os assuntos de forma crítica só é viável quando o aluno alcançou o letramento científico emancipatório (MARTINS, 2008) e passa a ser atuante no sentido de transformar não só a própria realidade em que vive, mas também se tornar um ser atuante na sociedade como um todo ou, no dizer de Freire (2018, p.53), “[...] o importante é que professor e alunos saibam que é preciso ter uma postura aberta, dialógica, questionadora dos enunciados “curiosos para o conhecimento"”.

O livro didático, como gênero discursivo, contém uma linguagem científica e segue convenções linguísticas socialmente organizadas em enunciados, unidades de comunicação verbal, estritamente delimitadas pela alternância dos atores sociais e que terminam por uma transferência da palavra ao outro. Estes enunciados estão inseridos em práticas sociais - constituindo formas fixas de comportamento para cada situação - e requerem certo tipo de linguagem e de comportamento convencionalizado socialmente e isso representa a forma como cada sujeito se comporta.

Devido a essa sujeição ideológica, consideramos os livros didáticos de Ciências, mediados pelo discurso científico-escolar, pertencentes ao gênero didático-pedagógico e compostos por um

[...] conjunto de diversos gêneros discursivos como leis, documentos oficiais, monumentos, parâmetros curriculares, propostas pedagógicas, livros, apostilas, enfim, o conjunto de textos que compõem e determinam o processo educacional. (CÂMARA, 2012, p. 2)

Deste modo, o gênero didático-pedagógico realiza-se no domínio discursivo educacional. O espaço escolar, como ambiente social, não funciona de forma diferente. O discurso veiculado pela escola passa pelo crivo da autoridade governamental, está prescrito em leis, decretos, parâmetros e colocados em livros didáticos que possuem uma linguagem cientificamente aceita, com a qual o aluno tem contato. 
Marcuschi (2007, p. 194) afirma: “[...] os domínios discursivos, além de produzirem modelos de comunicação, que se tornam estáveis, organizam também relações de poder”. Essas relações de poder determinam uma visão normativa de educação e, dentro desses domínios discursivos, "[...] formas de produção e distribuição do conhecimento nas atividades linguísticas" (MARCUSCHI, 2007, p. 63), estão os livros didáticos, escritos por autores/pesquisadores renomados e editorados por um mercado que reconhece a sua importância. São próprios dos saberes da ciência, mídia, divulgação, pesquisa e apresentação de formulações típicas, tais como recomendações aos professores com exercícios resolvidos, propostas de atividades práticas etc. (MARTINS, 2008).

Câmara (2012) nos diz que o discurso científico-escolar, presente no livro didático, é importante por apresentar uma linguagem validada pela ciência e com sentido de verdade indiscutível.

\section{Procedimentos teórico-metodológicos da pesquisa}

Com tais pressupostos descritos anteriormente, nos interessa entendermos a prática social do livro didático de Biologia, direcionado a jovens e adultos, explicando, logo em primeira mão, que optamos pela ACD (FAIRCLOUGH, 2001) porque, com este aporte, consideramos o discurso - linguagem escrita repleta de significado ideológico - linguagem em ação. A linguagem, e consequentemente o discurso, ocupa papel preponderante na vida social, em especial nas relações de poder como a estabelecida entre quem escreve um livro didático e o aluno, a quem é endereçado o livro. Essa relação pode ser encontrada nos textos, quando analisamos os aspectos gramaticais, já que usamos elementos gramaticais tais como os pronomes, verbos, substantivos etc. para elaborarmos qualquer tipo de texto e, em especial, o didático. Fairclough (2001) deixa claro o seu objetivo principal: estudar o significado existente por trás do texto como prática política e ideológica, que estabelece, mantém e transforma os significados evidentes nas relações de poder; olhar para os excluídos, no caso os alunos da EJA, e por meio do descortinar da linguagem tentar auxiliar estes a assumirem o papel social ao qual possuem direito. .

Por meio da ACD, buscamos trazer, com uma pesquisa de cunho qualitativo, elementos para discutir esse material didático de Ciências da Natureza, na disciplina de Biologia. Os pronomes "você" e "nós" apontam para uma interface sobre a importância da linguagem dentro do aspecto científico, em especial, no livro didático de Biologia, por não ser um material isento de ideologia. Os textos não são apenas resultados de atividades e práticas sociais. São elementos constitutivos e 
transformadores dessas práticas, permitem aos sujeitos a ressignificação de novos sentidos e novas relações com o conhecimento e com a sociedade (MARTINS, 2008).

Moreira (2013) argumenta ser o livro didático o componente escolar mais colaborativo para as práticas do Ensino de Ciências, ou seja, é o material de mais fácil acesso nas aulas de Ciências em nosso país. Pautados em estudos da educação, na importância histórica, na produção e consumo do livro didático na sociedade, de um modo geral, assumimos a postura de ser o livro didático o principal representante do discurso da ciência na escola.

No caso, nossa análise se detém no material impresso, distribuído pela Secretaria Estadual de Educação às escolas do Estado, no período de 2013, que possuem a modalidade de ensino EJA. Os alunos podem levar o material para casa e devolverem ao final do semestre letivo. É possível acessar, também, os módulos online pelo site http://projetoseeduc.cecierj.edu.br/eja/recurso.multimida-projessor/

Ressaltamos que o material da nossa pesquisa é o módulo 4, Ciências da Natureza, volumes 1 e 2, disciplina Biologia. O contexto no qual foi elaborado o material resulta de uma proposta, em 2013, implantada pelo Governo do Estado do Rio de Janeiro. Esta proposta previa a elaboração de livros e recursos multimídia numa parceria entre a Secretaria Estadual de Educação e a Fundação Centro de Ciências e Educação Superior (Cecierj). Os módulos foram divididos em Ciências Humanas e Ciências da Natureza. Nosso recorte foi o módulo 4, volumes 1 e 2, divididos em Química, Física e Biologia. É importante considerar que esses módulos não têm autoria evidente e não passam pelo crivo de escolha e seleção dos demais livros didáticos que circulam em território nacional e que compõem o acervo do Programa Nacional do Livro Didático.

O livro de Biologia deste módulo é o escolhido para compor nosso corpus de pesquisa, pois oferece materialidade discursiva para entendermos os discursos que poderiam fomentar no aluno o letramento científico (MARTINS, 2006) discutido anteriormente, e representa uma amostra de prática social, na visão da Análise Crítica do Discurso (RESENDE e RAMALHO, 2016). 


\title{
Dialogia
}

SANTOS, Josete Rocha dos; SILVA, Andréa Costa da. Uma análise discursiva do livro didático de Biologia na Educação para jovens e adultos

A seguir, o sumário do material analisado:

\author{
Sumário do módulo de Biologia \\ Volume 1 \\ Unidade 1 - O corpo, a pele, os músculos e o esqueleto \\ Unidade 2 - Sistemas respiratório e circulatório \\ Unidade 3 - Sistemas nervoso e imunológico \\ Unidade 4 - Sistema Urogenital \\ Unidade 5 - Sistema Digestório \\ Volume 2 \\ Unidade 1 - A energia do dia a dia \\ Unidade 2 - Interações ecológicas - a teia da vida \\ Unidade 3 - País tropical e bonito por natureza: os diferentes biomas \\ Unidade 4 - A árvore e os arbustos da vida \\ Unidade 5 - Cerveja, pão, Zé Gotinha, Soja e uma certa ovelha chamada Dolly: a Biotecnologia
}

As unidades foram lidas na íntegra e identificamos os enunciados em que havia o uso dos pronomes pessoais "você" e "nós" - que caracterizam as formulações presentes, nos materiais educativos. Levamos em conta que "[...] o uso da linguagem é moldado pelas intenções dos indivíduos" (FAIRCLOUGH, 2001, p. 83) e separamos, por meio de um levantamento qualitativo, para esta pesquisa, os contextos linguísticos nos quais o enunciador dirige-se ao aluno, como usa os pronomes "você" e "nós", de forma a se comprometer com seus enunciados, e se os usa para considerar o cotidiano deste aluno, na visão de Freire (2018), para ensinar o saber científico.

\section{Análise discursiva}

Acreditamos que as identidades sociais são descritas e construídas no discurso, também podendo ser reconstruídas, via discurso, se trazidas para o centro das aulas, em que alunos e alunas são identificados. Ao usar, em um texto, o pronome de tratamento "você", o enunciador se identifica com um menor grau de envolvimento a quem se dirige, no caso o aluno da EJA, pois se distancia da ação. (FAIRCLOUGH, 2001). Vejamos os excertos a seguir:

Você pode até pensar que o Cerrado é um ambiente pobre. Mas que nada! O Cerrado, pelo contrário, é um ambiente bastante diversificado. Apresenta diferentes domínios, cada um com sua vegetação típica: a mata ciliar, onde existe a peroba; o Cerrado, caracterizado pelo pau-santo, o campo-sujo, onde encontramos o murici; o campo cerrado, marcado pelas gramíneas; o campo cerrado rupestre, ambiente de diferentes orquídeas e bromélias. Talvez você se surpreenda se eu disser que o Cerrado é, atualmente, o segundo maior bioma brasileiro. Ocupa quase 2 milhões de quilômetros quadrados distribuídos por 12 estados: Rondônia, Pará, Maranhão, Piauí, Tocantins, Goiás, Bahia, Mato Grosso, Mato Grosso do Sul, Minas Gerais, São Paulo e Paraná, além do Distrito Federal." (Volume 2, Biologia da EJA, p. 73). 
Vemos como o significado identificacional (FAIRCLOUGH, 2001) está presente neste excerto por meio do pronome "você". Repare como inicia o trecho: "Você pode até pensar que o Cerrado é um ambiente pobre" e o "eu” quando diz "se eu disser que o Cerrado é, atualmente, o maior bioma brasileiro". O enunciador se coloca como alguém que conhece o assunto, mas não considera o aluno, que é visto de forma distanciada, no mesmo nível de conhecimento. Observe o segundo parágrafo, ao se dirigir, novamente, ao leitor, quando se usa o pronome "você" seguido do advérbio de dúvida "Talvez" e do verbo "surpreender", que expressa "surpresa", no seguinte enunciado: "Talvez, você se surpreenda se eu disser que o Cerrado é, atualmente, o segundo maior bioma brasileiro". Verificamos que este uso adverbial, acompanhado do verbo "surpreender", reforça uma suposição preconcebida de que o aluno não conhece, que está representado como paciente, não sabe o suficiente sobre o Cerrado brasileiro. Pressupõe-se, assim, a deficiência de conhecimento deste estudante da EJA. Contudo, ele, o sujeito dialógico, se considera tão sabedor sobre o assunto que utilizou uma postura distanciada ao usar o pronome pessoal "eu".

Embora não possuam escolaridade completa, os jovens e adultos que voltam a estudar depois de estarem no mercado de trabalho possuem uma bagagem cultural, e vemos, no excerto acima, que, com base nisso, o enunciador considerou o que estes alunos pensavam sobre o Cerrado. No entanto, há a desconstrução desse raciocínio com o enunciado "Mas que nada"! Com essa assertiva, preocupa-se em ampliar o conhecimento científico do aluno, por meio de escolhas lexicais apropriadas, ao usar nomes específicos como: mata ciliar, Cerrado, campo-sujo, campo cerrado e campo cerrado rupestre e, de forma bastante objetiva, caracteriza cada um destes domínios.

Os verbos usados no trecho destacado estão todos no presente do indicativo, demonstrando que o evento é atual e o conhecimento é transmitido de forma a não mostrar dúvidas do evento. No entanto, o enunciador precisa apresentar uma linguagem mais científica e de diálogo para levar o aluno a pensar onde e como usar este conhecimento. Observe o trecho em que o sujeito dialógico afirma que o Cerrado "Ocupa quase 2 milhões de quilômetros quadrados distribuídos por 12 estados [...]”. Nesse trecho, mostra-se um conhecimento abalizado sobre educação ambiental. Preocupa-se em transmitir informação para acrescentar um conhecimento científico útil ao aluno, mas o uso do pronome de tratamento "você" é feito de forma a mostrar que a ação é do outro e não do enunciador.

Já o pronome pessoal do caso reto "nós" indica um envolvimento maior, por parte do sujeito dialógico, na referida ação. Há uma tentativa de aproximação do sujeito com o interlocutor 


\section{Dialogia}

SANTOS, Josete Rocha dos; SILVA, Andréa Costa da. Uma análise discursiva do livro didático de Biologia na Educação para jovens e adultos

ao considerá-lo não como paciente, mas como agente da ação (BARROS, 2010), ao identificá-lo com o pronome "nós". Estas considerações são importantes na medida em que é necessário pensar neste jovem e adulto que voltam à sala de aula, depois de tanto tempo longe dela, e que precisam ter o seu direito de aplicar o saber científico nas práticas sociais do cotidiano (DI PIERRO, 2016), ser letrado cientificamente para atuar na sociedade. A linguagem pode favorecer este percurso se considerar a realidade do aluno. Na visão de Freire (2018), a linguagem deve "estimular a pergunta, a reflexão crítica" e a "dialogicidade ${ }^{1}$ deve ser aberta, curiosa, indagadora e não apassivada" (FREIRE, 2018, p. 83). Com base neste pensamento de Freire e associado à visão de Fairclough (2001), para quem os excluídos têm direitos, que passam pelo crivo da linguagem, que deve fazêlos pensar e atuar, apresentamos, a seguir, outro excerto para análise.

Entender os padrões de relações históricas e evolutivas entre as linhagens da diversidade biológica é fundamental, pois existe uma dependência entre as características que espécies descendentes compartilham e a idade de seu ancestral comum. Existem processos evolutivos relacionados à diversificação das linhagens que, se compreendidos, fornecem aos pesquisadores pistas sobre o compartilhamento de características.

Por exemplo, entendendo os padrões de ancestralidade, em comum, saberemos que, se uma espécie apresenta glândulas mamárias, ela será um vertebrado, um animal e um eucarionte. Sabendo uma característica, podemos prever outras, muitas outras! As espécies ancestrais passam todo o genoma para espécies descendentes. Por isso, não apenas as características marcantes, mas também aquelas características que nós nem conhecemos, ainda, são compartilhadas pelos ramos de uma árvore filogenética.

Uma questão interessante que surge quando aliamos filogenia à história é que podemos inferir questões importantes sobre outras características que não foram usadas para inferir a filogenia.

Uma coisa importante é que, a partir do momento em que contamos a história da vida por meio de uma árvore filogenética, nomear grupos da diversidade vira uma tarefa relativamente simples. Basta nomearmos os ramos da filogenia e juntarmos a filogenia com a taxonomia em uma sistemática filogenética. (Volume 2, Biologia da EJA, p. 105).

Percebe-se, no trecho acima, a preocupação de como o significado identificacional se apresenta por meio do pronome pessoal "nós" com o sentido de proximidade. A maior parte do excerto se apresenta com esta tentativa de aproximação.

O enunciador procura, por meio do conceito científico de árvore filogenética e como podemos aliar o estudo da filogenia à história de vida do indivíduo, considerar o cotidiano do aluno. Entendendo filogenia como sendo o estudo da ancestralidade das espécies, podemos ver que o autor do texto usa um vocabulário específico a fim de enriquecer o conhecimento do estudante e leva-lo à construção do raciocínio. Observe o trecho: “[...] existem processos evolutivos

\footnotetext{
${ }_{1}^{1}$ Dialogicidade é um conceito de Bakhtin, retomado por Fairclough (2001, p. 92), e que tem a ver com "a comunicação interativa entre os seres, responsável pela construção da imagem que criamos do outro".
} 
relacionados à diversificação das linhagens que, se compreendidos, fornecem aos pesquisadores pistas sobre o compartilhamento de características".

No segundo parágrafo, o significado identificacional se apresenta por meio dos verbos na primeira pessoa do plural a partir do trecho "[...] entendendo os padrões de ancestralidade, em comum, saberemos que, se uma espécie [...]”. Destacamos os verbos, na primeira pessoa do plural no trecho acima, ressaltando que, ao final do segundo parágrafo, usa, explicitamente, o pronome pessoal "nós", seguido do verbo "conhecer": "aquelas características que nós nem conhecemos, ainda, são compartilhadas pelos ramos de uma árvore filogenética". Analisando o enunciado, percebemos um sujeito dialógico interessado em se referir não apenas ao contexto extraverbal. Está interessado em não apenas veicular um conhecimento científico, mas em promover um conhecimento que faça o aluno se perceber como parte integrante de uma cadeia filogenética e com condições cognitivas para, a partir desses conhecimentos, ampliar o seu universo como cidadão atuante em uma sociedade que preconiza a Educação Ambiental. Novamente, percebe-se a articulação do conteúdo com as funções da EJA, propostas pela LDB, Lei 9394/96, BRASIL, (1996). Há a possibilidade de aplicar um conteúdo que seja importante na construção de uma posição social emancipatória. Vemos, assim, que neste trecho, ao contrário do primeiro, o sujeito dialógico, ao se identificar com o interlocutor usando os verbos na primeira pessoa do plural, enuncia um maior envolvimento com o enunciado e considera o olhar do aluno, com quem dialoga, considera seus valores, coloca-se em seu lugar, e principalmente, se identifica com este aluno (FAIRCLOUGH, 2001).

Com esses excertos, percebemos uma tentativa de o enunciador se identificar com o aluno, na maior parte das vezes, usando o pronome "nós". Vemos, assim, como os desafios pedagógicos para a Educação de Jovens e Adultos são perceptíveis na linguagem do livro didático de Biologia. Observamos, como sugere Paulo Freire, o estímulo à curiosidade do educando, valorizando "[...] o seu gosto estético, a sua inquietude, a sua linguagem, mais precisamente, a sua sintaxe e a sua prosódia” (2018, p.31). É por meio desta tentativa de uma linguagem de maior proximidade que fica garantido o direito ao ser humano de construir a sua independência enquanto ser atuante na sociedade.

\section{Considerações finais}

Neste artigo, apresentamos um recorte da pesquisa, numa análise não exaustiva, uma vez que o corpus era composto por todos os textos do livro de Biologia, com o perfil anteriormente descrito. Acreditamos que ao evidenciar como o discurso do livro didático utiliza o significado 
identificacional (FAIRCLOUGH, 2001), oferecemos evidências para que se passe a considerar o contexto sócio-histórico do interlocutor e sua visão de mundo. O sujeito dialógico, percebido nesta amostra, ao usar o pronome de tratamento "você", parte de uma postura na qual pressupõe desconhecimento do aluno em relação ao conteúdo científico veiculado, e se coloca numa postura distanciada, algo que se contrapõe às propostas atuais para o Ensino de Ciências, em especial no Ensino Médio. No entanto, há trechos em que o sujeito dialógico coloca-se como parte da prática social ao usar verbos na primeira pessoa do plural ou, explicitamente, o pronome pessoal do caso reto "nós", identifica-se com o leitor e expressa tentativa de dialogicidade com o aluno da EJA.

Pensamos que esse aluno precisa de um material com uma linguagem dialógica mais rica e estimulante do que a apresentada. Essa linguagem, mais dialógica, que desejamos ver nos livros de Ciências, é aquela que possibilita ao aluno refletir sobre o conteúdo com criticidade (MARTINS, 2008). Para se chegar a isso, o discurso do livro, em especial de Biologia, precisa ser mais bem trabalhado e se aproximar mais do universo do aluno, é preciso haver mais trechos em que o aluno seja identificado como agente, aquele que já tem um conhecimento e vai ser acrescentado um viés científico. Para isso, outros elementos de dialogicidade precisam estar presentes em materiais educativos para que estes estudantes sejam motivados a fazerem uma leitura de mundo no qual estão inseridos, buscando o exercício da autonomia, a tomada de decisão e a participação social em contextos que relacionam saúde e ambiente, para auxiliá-lo a ser letrado e um ser autônomo na sociedade onde vive (FREIRE, 2018).

Ao observarmos o material didático, podemos nos indagar se há assimilação da EJA, nas políticas de juventude, que tenda a reproduzir uma visão limitada, desta modalidade de estudo, que pode ser percebida, possivelmente, pela atenção dada a um público marcado pela vivência de diferentes formas de exclusão social. Esse, talvez, seja um dos grandes desafios para os educadores: incorporar os jovens como sujeitos de direitos, proporcionando-lhes uma educação significativa, que auxilie na construção da cidadania como participação ativa na sociedade do século XXI. Esse desafio se contrapõe a uma tendência de conceber a EJA como uma educação de "segunda categoria", que pode ser implementada de forma descuidada e sem grandes custos. Essa perspectiva não reconhece os seus alunos como sujeitos de direitos, mas como beneficiários da ação filantrópica e assistencial do Estado mínimo de direito, proposta do estado neoliberal.

Conforme iniciamos este trabalho, retomamos Gadotti (2013) ao dizer que "os Direitos Humanos são interdependentes" e, dentre eles, está o direito à educação, inserido nos direitos sociais: direito a um emprego digno, à moradia, a votar e ser votado e, também, a ter condições de ascensão social. Para ter acesso a isso, o aluno da EJA, normalmente pertencente a 


\section{Dialogia}

SANTOS, Josete Rocha dos; SILVA, Andréa Costa da. Uma análise discursiva do livro didático de Biologia na Educação para jovens e adultos

grupos sociais mais vulneráveis, precisa e tem direito a ter uma educação, com um livro didático contendo conhecimentos biológicos, que o torne consciente do seu corpo e do meio ambiente em que vive para possibilitá-lo superar a pobreza e a exclusão social. Pensar nesta linguagem mais pautada no significado identificacional, voltada à educação de jovens e adultos, é orientar esses sujeitos para a autonomia, possibilitando sua independência em decidir, capacitando-os a ações críticas em seu espaço existencial.

Assim, reiteramos a preocupação por garantir a luta pelo direito à educação, uma vez que não está separada da luta pelos demais Direitos Humanos.

\section{Referências}

ALVARENGA, M. S. Sentidos da cidadania: políticas de educação de jovens e adultos. Rio de Janeiro: Eduerj, 2010.

ARROYO, M. A educação de jovens e adultos em tempos de exclusão. Alfabetização e Cidadania. São Paulo, v. 11, abr. 2001, p. $9-20$.

BARROS, D. C. E. Significados identificacionais: ethos e espaço político na construção discursiva da realidade social feminina. Universidade Estadual de Maringá: D.E.L.T.A., 2010, p. 505 - 525.

BRASIL. Lei de Diretrizes e Bases da Educação Nacional no 4024 de 20 de dezembro de 1996. Disponível em https://www2.senado.leg.br/bdsf/bitstream/handle/id/70320/65.pdf: Acesso em: 12 mar 2020.

BRASIL. Conselho Nacional de Educação. Câmara de Educação Básica. Parecer CEB 11/2000. Diretrizes curriculares nacionais para a educação de jovens e adultos.

BRASIL. Conselho Nacional de Educação. Câmara de Educação Básica. Resolução CEB 1/2000. Diretrizes curriculares nacionais para a educação de jovens e adultos.

CÂMARA,N. S. O gênero didático-pedagógico: uma caracterização. In: Congreso de la delegación argentina de la Asociación de Linguistica y Filologia de America Latina y Jornadas Internacionales de investigación en filología hispánica, 2012, La Plata. Caderno de resumos. La `Plata, 2012.

CARRANO, P. C. et al. Trajetórias truncadas, trabalho e futuro: jovens fora de série na escola pública de ensino médio. In: Educação Pesquisa. São Paulo: v. 41, n. especial, p. 1439-1454, dez. 2015.

CHOULIARAKI, L; FAIRCLOUGH, N. Discourse in Late Modernity. Retbingking critical discourse analysis. Edinburgh: Edinburgh University Press, 1999.

DI PIERRO, M. C. e HADDAD, S. Transformações nas politicas de Educação de Jovens e Adultos no Brasil no início do terceiro milênio: uma análise das agendas nacional e internacional. Cad. Cedes, Campinas, v. 35, n. 96, p. 197 - 217, maio -ago, 2015.

FAIRCLOUGH, N. Discurso e mudança social. Brasília: Universidade de Brasília, 2001. 


\section{Dialogia}

SANTOS, Josete Rocha dos; SILVA, Andréa Costa da. Uma análise discursiva do livro didático de Biologia na Educação para jovens e adultos

FAIRCLOUGH, N. Analysing Discourse: textual analysis for social research. London: Routledge, $2003^{\mathrm{a}}$.

FREIRE, P. Pedagogia da autonomia: saberes necessários à prática educativa. 36ª ed. São Paulo: Paz e Terra, 2018.

GADOTTI, M. Educação de adultos como direito humano. EJA em debate. Florianópolis: ano 2 n. 2, jul 2013. Disponível em: http://periodicos. Ifsc.edu.br/index.php/EJA. Acesso em: 12 mar 2020

GOVERNO DO ESTADO DO RIO DE JANEIRO. Secretaria Estadual de Educação. Nova EJA - Educação para Jovens e Adultos - Ciências da Natureza e suas Tecnologias - volumes 1 e 2.

KRASILCHIK, M. Reformas e realidade: o caso do ensino de ciências. São Paulo: Perspectiva, v. 14, n. 1, 2000.

MACHADO, Maria Margarida. A educação de jovens e adultos - após vinte anos da Lei no 9.394, de 1996. Revista Retratos da Escola. Brasília, v. 10, n. 19, p. 429 - 451, jul/dez, 2016.

Disponível em http//www.esforce. org. br. Acesso em: 12 mar 2020

MARCUSCHI, Luiz Antônio. Cognição, linguagem e práticas interacionais. Rio de Janeiro: Editora Lucerna, 2007.

MARTINS, I. Alfabetização cientifica: metáfora e perspectiva para o ensino de ciências. XI Encontro de Pesquisa em Ensino de Física. Curitiba, 2008. In: www.ciencia.mao.up.br/dados/epef/alfabetização científicam.trabalho.pdf: Acesso em: 12 mar 2020

MOREIRA, M. C. A. A recontextualização do discurso da pesquisa em educação em ciências em uma coleção didática de ciências. 2013. 169p. Tese (Doutorado em Educação em Ciências \& Saúde) - Núcleo de Tecnologia Educacional para a Saúde, Rio de Janeiro, 2013.

RESENDE, V; RAMALHO, V. Análise de discurso crítica. São Paulo: Editora Contexto, 2016.

Recebido em: 31 mar. 2020/ Aprovado em: 30 jul. 2020

\section{Cite como}

\section{(ABNT NBR 6023:2018)}

SANTOS, Josete Rocha dos; SILVA, Andréa Costa da. Uma análise discursiva do livro didático de Biologia na Educação para jovens e adultos. Dialogia, São Paulo, n. 35, p. 7-21, maio/ago. 2020.

Disponível em: https://doi.org/10.5585/dialogia.n35.16924.

\section{American Psychological Association (APA)}

Santos, J. R., \& Silva, A. C. da. (2020, maio/ago.). Uma análise discursiva do livro didático de Biologia na Educação para jovens e adultos. Dialogia, São Paulo, 35, p. 7-21.

https://doi.org/10.5585/dialogia.n35.16924. 